\title{
Wetlands of the World: the next installment
}

\author{
Dennis Whigham $\cdot$ Jos T. A. Verhoeven
}

Published online: 24 February 2009

(C) The Author(s) 2009. This article is published with open access at Springerlink.com

In 2004 Wetlands Ecology and Management (WEM) launched a new series devoted to descriptions of the world's wetlands with a goal of publishing review articles, with an ecological focus, of wetlands in particular geographic areas that have not been described at all, have not been described in English or have not been recently described. The first article in the series (Wetlands of Central America by Aaron Ellison) has been widely cited. In this volume of WEM the next articles in the series appear.

Joanna Ellison (Wetlands of the Pacific Island region) describes seven types of wetlands over a vast region that encompasses 21 countries and territoriesonly five being signatories to the Ramsar convention. She describes large-scale patterns in diversity and provides insight into the quality and amount of information that is available for wetlands in the region. A variety of human activities are impacting the regions' wetlands and Ellison describes a range of activities that are needed if wetlands in the region are to be conserved and used wisely. Similar to the article by Aaron Ellison, Joanna Ellison provides a compilation of important references that can be used to gain further insight into wetlands of Pacific Islands.

Al-Hilli and colleagues (An assessment of vegetation and environmental controls in the 1970s of the Mesopotamian wetlands of southern Iraq) provide an historical view of prior conditions in the vast Mesopotamian Plain wetlands prior to the large-scale destruction that has occurred in recent decades. This valuable contribution serves, in part as a benchmark, for gauging ongoing restoration efforts.

These two articles are representative of the types of descriptions that Jos and I seek for the series. While we continue to search for authors to describe the world's vast diversity of wetlands we also encourage the readers to suggest topics and potential authors. If you have suggestions for the series, please contact Jos or me.

Open Access This article is distributed under the terms of the Creative Commons Attribution Noncommercial License which permits any noncommercial use, distribution, and reproduction in any medium, provided the original author(s) and source are credited.

D. Whigham ( $\square)$

Smithsonian Environmental Research Center,

Edgewater, MD, USA

e-mail: whighamd@si.edu

J. T. A. Verhoeven

Utrecht University, Utrecht, The Netherlands

e-mail: j.t.a.verhoeven@uu.nl 